\title{
Study of efficacy of compression suture in the surgical management of atonic PPH
}

\author{
Shrinivas N. Gadappa, Yogita B. Gavit*, Deepika Sharma, Rasika Mahajan
}

Department of Obstetrics and Gynecology, Government Medical College, Aurangabad, Maharashtra, India

Received: 31 July 2018

Accepted: 29 August 2018

*Correspondence:

Dr. Yogita B. Gavit,

E-mail: dryogita1990@gmail.com

Copyright: (C) the author(s), publisher and licensee Medip Academy. This is an open-access article distributed under the terms of the Creative Commons Attribution Non-Commercial License, which permits unrestricted non-commercial use, distribution, and reproduction in any medium, provided the original work is properly cited.

\begin{abstract}
Background: Study was conducted to analysis efficacy of compression suture in the surgical management of Atonic PPH. It's prospectively carried out with 60 cases required compression suture in managing Atonic PPH. Atonic uterus is preventable cause of maternal mortality and morbidity constituting $80 \% \mathrm{PPH}$ cases.

Methods: Prospective study carried out at tertiary care center for studying efficacy of compression suture in the surgical management of atonic PPH for one year, started after approval from ethical committee.

Results: Compression suture is effective in managing atonic PPH. out of 60 cases, 4 patient's required obstetric hysterectomy as a last resort to control Atonic PPH. Uterus was conserved in $93.3 \%$ of cases.

Conclusions: Development of compression suture technique has proved to be effective in the control of massive Atonic PPH not responding to medical management is an alternative to hysterectomy when timely applied. It proves to be valuable addition for surgical treatment of $\mathrm{PPH}$ and for saving uteri after medical management of PPH failed. Authors can adopt compression suture as a mid-step before resorting to uterine devascularisation or hysterectomy when medical line of management fails. Resident doctors in teaching institutes must be well trained in this technique.
\end{abstract}

Keywords: Atonic PPH, Compression sutures, Devascularisation, Hysterectomy

\section{INTRODUCTION}

Postpartum hemorrhage means loss of more than $500 \mathrm{ml}$ of blood from or into the genital tract in the first 24 hours after vaginal delivery or more than $1000 \mathrm{ml}$ following caesarean delivery. ${ }^{1}$ But intraoperative estimation of blood loss is notoriously inaccurate. Thus, the American College of Obstetricians and Gynecologists defines it as a decrease in hematocrit of more than $10 \%$ from the predelivery status. $^{2}$

In India $25.6 \%$ maternal death is due to postpartum

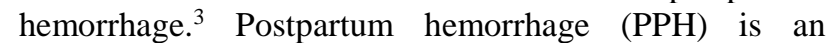
obstetric emergency that occurs in 1 to $5 \%$ of both vaginal and caesarean deliveries, with sequel such as hemodynamic shock, renal failure, acute respiratory distress syndrome, coagulopathy, and Sheehan's syndrome.

Atonic uterus is preventable cause of maternal mortality and morbidity constituting $80 \%$ PPH cases. The traditional management of this condition begins with conservative methods like bimanual compression, uterine massage, medical therapy with uterotonic agents, uterine tampanode with balloons and occasionally arterial embolisation, the failure of which often mandates surgical intervention. Surgical measure such as ligation of major pelvic vessels demands a rarely used skill possessed by few registrars. In the event of intractable hemorrhage despite the above measures, hysterectomy is usually final resort. To overcome PPH in 1997 Balogun Lynch Christopher described use of uterine compression 
stitch to uterine atony in massive obstetrics hemorrhage with objective of compressing the uterus without devascularisation. Since its invention in 1997, the Blynch technique has been used successfully in approximately 1,300 cases worldwide. ${ }^{4}$ There are other types of compression sutures also like Pereria suture, Cho suture. This study aims studying the effectiveness of compression suture in the surgical management of atonic PPH. As it's a tertiary care institute with huge load of obstetrics, author decided to conduct the study on compression suture in control of atonic PPH and to study its types and its efficacy in terms of uterine saving surgery, to study commonly applied compression suture in management of atonic PPH and study effects and side effects of the compression suture.

\section{METHODS}

Present study is prospective study carried out at tertiary care center for studying efficacy of compression suture in the surgical management of atonic PPH for 1 year. Study has been started after approval from ethical committee.

\section{Inclusion criteria}

- All patients of atonic PPH who required surgical management in the form of compression suture.

- Patients delivered vaginally or by caesarian section landing in atonic PPH who required compression suture.

\section{Exclusion criteria}

- Patients referred from outside with compression suture.

- Patients of traumatic PPH.

- Patients of PPH due to coagulation failure.

\section{Statistical analysis}

Maternal and fetal outcome were recorded. In case of maternal death time interval between intervention and death recorded. Detail analysis of maternal deaths was done. Statistical analysis was done as percentage. The data of patients were collected, compiled and entered in MS Excel 2008 worksheet.

\section{RESULTS}

Compression suture was required in $50 \%$ of the cases in primipara patients in study population because of the associated risk factor in pimipara landing in atonic PPH. From present study it was seen that incidence of atonic $\mathrm{PPH}$ requiring compression suture in primipara and multipara was almost same. Hence $50 \%$ were primipara and $46.6 \%$ were multipara. Hence from this, authors conclude that parity do not influence as etiology for atonic PPH.

Table 1: Distribution of cases according to parity.

\begin{tabular}{|lll|}
\hline Parity & No. of cases $(n=60)$ & $\%$ \\
\hline Primi & 30 & 50 \\
\hline Mutipara & 28 & 46.6 \\
\hline Grandmultipara & 2 & 3.3 \\
\hline Total & 60 & 100 \\
\hline
\end{tabular}

In present study, LSCS was mode of delivery in $88 \%$ cases, vaginal was mode of delivery in $6.7 \%$ and outside delivery in $5 \%$. Hence compression sutures applied in LSCS for managing atonic PPH. Authors conclude in present study that majority of compression suture were seen in LSCS patients.

Table 2: Distribution of cases according to mode of delivery.

\begin{tabular}{|lll|}
\hline Mode of delivery & Number of cases $(\mathbf{n}=60)$ & $\%$ \\
\hline Vaginal & 4 & 6.7 \\
\hline Lscs & 53 & 88.3 \\
\hline Outside delivery & 3 & 5 \\
\hline Total & 60 & 100 \\
\hline
\end{tabular}

Table 3: Distribution of causative factors for PPH among study population.

\begin{tabular}{|c|c|c|c|c|}
\hline Causative factors & Primipara & Multipara & Total cases $(n=60)$ & $\%$ \\
\hline Abruption & 5 & 8 & 13 & 16.67 \\
\hline Placenta previa & 2 & 5 & 7 & 8.9 \\
\hline Severe pre-eclampsia & 8 & 8 & 16 & 20.5 \\
\hline Eclampsia & 3 & 2 & 5 & 6.4 \\
\hline Prolonged labour & 4 & 1 & 5 & 6.4 \\
\hline Failure of induction & 3 & 2 & 5 & 6.4 \\
\hline Big baby & 3 & 1 & 5 & 5.13 \\
\hline Multiple pregnancy & 3 & 1 & 4 & 5.13 \\
\hline Thrombocytopenia & 4 & 0 & 4 & 5.13 \\
\hline Others & 4 & 6 & 10 & 12.82 \\
\hline Total & 42 & 36 & 78 & 100 \\
\hline
\end{tabular}


$\mathrm{n}=60$ this number is not matching in Table 3 because risk factors for Atonic PPH $>1$ in few cases. Example, Primi gravida with eclampsia with abruption with failure of induction. Major risk factor accounting to postpartum haemorrhage in primi para was severe pre-eclampsia, eclampsia and abruption. Major risk factor accounting to Post-Partum Hemorrhage in multipara was severe preelcampsia, abruption and placenta previa.

Table 4: Distribution according to amount of blood loss.

\begin{tabular}{|lll|}
\hline Blood loss & No. of cases & Percentage \\
\hline Class $1<1000 \mathrm{ml}$ & 9 & 15 \\
\hline Class 2 $1500-1001 \mathrm{ml}$ & 26 & 43.3 \\
\hline Class 3 $1501-2000 \mathrm{ml}$ & 16 & 26.6 \\
\hline Class 4 2001-2500 ml & 9 & 15 \\
\hline Total & 60 & 100 \\
\hline
\end{tabular}

$43 \%$ of the patients had blood loss in the range of 1000 to $1500 \mathrm{ml}$ which can attribute to timely application of compression suture. Amount of blood loss is measured by collecting blood in kidney tray and measuring it. Authors conclude in present study timely application of compression sutures has reduced the blood loss, thus thereby contributing in management of atonic $\mathrm{PPH}$.

Table 5: Distribution of cases according to time interval between PPH and compression suture.

\begin{tabular}{|lll|}
\hline Total time interval & No. of cases $(n=60)$ & Percentage \\
\hline$<2$ hours & 56 & 93.3 \\
\hline$>2$ hours & 4 & 6.6 \\
\hline Total & 60 & 100 \\
\hline
\end{tabular}

Maximum cases (56) underwent Compression suture for PPH in less than 2 hours. Among the 4 cases 3 cases were referred from outside and one delivered in present institute had atonic PPH after 2 hours. Maximum time interval between PPH and compression Suture was 5 hours. Authors conclude in present study timely application of compression sutures has reduced the blood loss, thus thereby contributing in management of atonic $\mathrm{PPH}$.

Table 6: Distribution according to type of compression suture.

\begin{tabular}{|lll|}
\hline $\begin{array}{l}\text { Type of compression } \\
\text { suture }\end{array}$ & $\begin{array}{l}\text { No. of cases } \\
(\mathbf{n}=60)\end{array}$ & \begin{tabular}{l} 
Percentage \\
\hline B Lynch suture
\end{tabular} \\
$\begin{array}{l}\text { Arulkumaran and } \\
\text { Hayman suture }\end{array}$ & 45 & 13.3 \\
\hline Pereria suture & 1 & 75 \\
\hline Cho suture & 6 & 1.6 \\
\hline Total & 60 & 1 \\
\hline
\end{tabular}

Most commonly applied compression suture study population is modified B lynch (Arulkumaran and
Hayman suture) in the $75 \%$ of the cases because of the simplicity of the application, easy technique for beginners to apply thereby aids in managing atonic $\mathrm{PPH}$. While $1.6 \%$ cases underwent Pereria suture, $10 \%$ cases underwent cho suture, Pereria suture, cho suture are difficult technique as compared to Arulkumaran and Hayman suture.

Table 7: Distribution of cases according to associated procedure performed.

\begin{tabular}{|lll|}
\hline Procedure & $\begin{array}{l}\text { No. of cases } \\
(\mathrm{n}=60)\end{array}$ & $\%$ \\
\hline $\begin{array}{l}\text { Compression suture alone } \\
\begin{array}{l}\text { Vaginal exploration followed } \\
\text { by compression suture }\end{array}\end{array}$ & 38 & 63.3 \\
\hline $\begin{array}{l}\text { Compression suture followed } \\
\text { by internal iliac artery ligation }\end{array}$ & 15 & 5 \\
\hline $\begin{array}{l}\text { Compression suture followed } \\
\text { by obstetrics hysterectomy }\end{array}$ & 4 & 25 \\
\hline Total & 60 & 6.7 \\
\hline
\end{tabular}

In present study PPH was controlled by compression suture in $63 \%$ cases. Most common associated procedure was compression suture with Internal Iliac Artery Ligation (IIAL). 5\% cases had vaginal exploration followed by compression suture, $25 \%$ case had compression Suture followed by internal iliac artery ligation, $6.7 \%$ case had compression suture followed by obstetrics hysterectomy. Hence authors conclude that Atonic PPH is managed alone by compression sutures in present study.

Table 8: Distribution of cases showing efficiency of compression suture as uterine salvage surgery.

\begin{tabular}{|lll|}
\hline Uterine salvage & No. of cases $(n=60)$ & Percentage \\
\hline Uterine conserved & 56 & 93.3 \\
\hline Hysterectomy & 4 & 6.7 \\
\hline Total & 60 & 100 \\
\hline
\end{tabular}

Out of 60 cases only 4 patients required obstetric hysterectomy as a last resort to control Atonic PPH. Uterus was conserved in $93.3 \%$ of cases. So, authors conclude that in present study application of compression sutures for managing atonic PPH aids in conserving uterus.

Table 9: Distribution of cases according to complications.

\begin{tabular}{|lll|}
\hline \multirow{3}{*}{ Type of complication } & No. of Cases \\
\hline \multirow{3}{*}{ Minor } & Fever & 4 \\
\cline { 2 - 3 } & Wound Gape & 2 \\
\cline { 2 - 3 } Major & Haematoma & 0 \\
\hline \multirow{3}{*}{} & Vesicovaginal fistula & 0 \\
\cline { 2 - 3 } & Deep vein thrombosis & 0 \\
\cline { 2 - 3 } & Uterine wall necrosis & 0 \\
\hline
\end{tabular}


In present study out of 60 patients four patients had postoperative pyrexia and two patients had wound gape. No patient had major complication. Relaparotomy is not required in any of the cases. So, authors conclude that surgical management of atonic PPH that is compression sutures has no major complication like vescio vaginal fistula, deep vein thrombosis, uterine wall necrosis

\section{DISCUSSION}

Primary PPH is a common obstetric emergency which can lead to emergency hysterectomy in patients with treatment resistant, life threatening bleeding. Surgical methods of controlling uterine bleeding by inserting compression sutures have been developed to reduce the incidence of emergency hysterectomy and to preserve fertility in these patients. While treating massive atonic postpartum hemorrhage minute to minute evaluation of patient is very essentials at no cost patient should be subjected to medical line of management if golden period for medical management is crossed. In failed medical method immediate switch over to intrauterine tamponade and compression sutures. In this study; authors have evaluated different types of compression suture technique for achieving uterine compression in atonic PPH. The technique is easy to perform during emergency condition at caesarean section. They are safe and relatively inexpensive procedure. Furthermore, the procedure enabled to avoid emergency peripartum hysterectomy and thus preserve their fertility and obviate any other surgical complications of hysterectomy in these circumstances. The timely application of this suture also reduced the need for blood transfusion and its associated complications. The various parameters of present study have been compared with other studies:

Table 10: Mode of delivery.

\begin{tabular}{|c|c|c|}
\hline Study & \multicolumn{2}{|c|}{ Mode of delivery } \\
\hline & Vaginal & LSCS \\
\hline Quahba et $\mathrm{al}^{6}$ & 3 & 17 \\
\hline Khatoon et $\mathrm{al}^{5}$ & 9 & 6 \\
\hline Kulsange $\mathrm{P}$ et al ${ }^{15}$ & 7 & 46 \\
\hline Present study & 7 & 53 \\
\hline
\end{tabular}

In Khatoon study compression suture was applied on 9 cases $(60 \%)$, after vaginal delivery and on 6 cases $(40 \%)$ during LSCS as sample size was less in the study. ${ }^{5}$ In Quahba, Punam and present study compression suture was most commonly applied after LSCS. ${ }^{6,15}$ This may be because of aggressive management of PPH during LSCS.

Table 11: Causative factors.

\begin{tabular}{|c|c|c|c|c|}
\hline Causative factors & Nalini et al $^{7}$ & Kulsange $P$ et al $^{15}$ & Kalkal $\mathbf{N}$ et al ${ }^{16}$ & Present study \\
\hline Abruption & 4 & 0 & 9 & 13 \\
\hline Placenta previa & 0 & 8 & 0 & 7 \\
\hline Severe pre-eclampsia & 17 & 16 & 0 & 16 \\
\hline Eclampsia & 8 & 4 & 0 & 5 \\
\hline Prolonged labour & 18 & 6 & 10 & 5 \\
\hline Failure of induction & 0 & 0 & 0 & 5 \\
\hline Prolonged PROM & 0 & 7 & 6 & 5 \\
\hline Big baby & 0 & 0 & 0 & 4 \\
\hline Multiple pregnancy & 7 & 0 & 2 & 4 \\
\hline Thrombocytopenia & 0 & 0 & 0 & 4 \\
\hline Others & 9 & 9 & 3 & 10 \\
\hline
\end{tabular}

Table 12: Amount of blood loss.

\begin{tabular}{|ll|}
\hline Study & Blood loss $(\mathrm{ml})$ \\
\hline Allerhdin et $\mathrm{al}^{14}$ & 3500 \\
\hline Hackenthal et al $^{10}$ & $2500(2000-3500)$ \\
\hline${\text { Koh et } \mathrm{al}^{4}}^{\text {Tarq et al }}$ & $2200(800-5000)$ \\
\hline Marasingh et al $^{9}$ & $1500-2000$ \\
\hline Kalkal N et al $^{16}$ & $1800-2200$ \\
\hline Present study & $1000-1500$ \\
\hline
\end{tabular}

In Nalini study main pathology during pregnancy responsible for PPH was prolonged labour followed by pre-eclampsia in Punam study most common causative factor was pre-eclmapsia. ${ }^{5,7}$ In Nidhi study most common causative factor was prolonged labour followed by abruption. In present study most common causative factor was severe pre-eclampsia followed by abruption.

Average blood loss was 1000-1500 $\mathrm{ml}$ which is comparable to mean blood loss in Nidhi, Tarq, and Marasingh study and much lesser than other studies. (Allerhdin, Hackenthal, Koh). ${ }^{4,8-10,14,16}$ This might be the result of difference in the threshold to resort to uterine compression suturing when medical management fails in achieving adequate uterine retraction. This finding also explains that timely application compression sutures decreases blood loss and need for transfusion. 
Table 13: Success rate of compression suture.

\begin{tabular}{|c|c|}
\hline Study & Success rate (\%) \\
\hline Allerhdin et $\mathrm{al}^{14}$ & 72 \\
\hline Mohini et al ${ }^{11}$ & 100 \\
\hline Quahba et $\mathrm{al}^{6}$ & 95 \\
\hline Hackenthal et al ${ }^{10}$ & 100 \\
\hline Koh et $\mathrm{al}^{4}$ & 86 \\
\hline Khatoon et $\mathrm{al}^{5}$ & 93.2 \\
\hline Tarq et $\mathrm{al}^{8}$ & 95 \\
\hline Marasingh et $\mathrm{al}^{9}$ & 75 \\
\hline Majumdar et al ${ }^{12}$ & 100 \\
\hline Anamika et al $^{12}$ & 100 \\
\hline Kulsange $\mathrm{P}$ et $\mathrm{al}^{15}$ & 94 \\
\hline Kalkal $\mathrm{N}$ et al ${ }^{16}$ & 93.3 \\
\hline Present study & 93.3 \\
\hline
\end{tabular}

Success rate in present study was $93.3 \%$ with similar results in study by Quahba, Khatoon, Tarq, and Punam and Nidhi. ${ }^{5,6,8,15,16}$ Only 4 patients required hysterectomy as PPH was not controlled with compression suture. Study conducted on compression suture to control PPH by Mohini, Hackenthal, Mujumdar, Anamika shows $100 \%$ success rate. ${ }^{10-12}$ Success rate with compression suture range from $82-95 \%$. The difference in success rate could be because of difference in patient selection criteria.

Table 14: Complication.

\begin{tabular}{|lll|l|}
\hline Complication & $\begin{array}{l}\text { Ghodake } \\
\text { et al }{ }^{13}\end{array}$ & $\begin{array}{l}\text { Kulsange P } \\
\text { et al }^{15}\end{array}$ & $\begin{array}{l}\text { Present } \\
\text { study }\end{array}$ \\
\hline Fever & 5 & 2 & 4 \\
\hline $\begin{array}{l}\text { Wound gape } \\
\text { Hematoma }\end{array}$ & 3 & 1 & 2 \\
\hline $\begin{array}{l}\text { formation } \\
\text { Deep vein } \\
\text { thrombosis }\end{array}$ & 0 & 0 & 0 \\
\hline $\begin{array}{l}\text { Vesico } \\
\text { vaginal fistula }\end{array}$ & 0 & 0 & 0 \\
\hline $\begin{array}{l}\text { Uterine wall } \\
\text { necrosis }\end{array}$ & 0 & 0 & 0 \\
\hline
\end{tabular}

Prospective study conducted by Ghodake 31 patients underwent compression suture out of which 5 patients had post-operative pyrexia, 3 patients had surgical wound gape. In Punam study, 50 patients underwent modified Blynch compression suture, 2 patient had post-operative pyrexia and 1 patent had wound gape. ${ }^{5}$ In present study 60 patient underwent compression suture, 4 patients had post-operative pyrexia and 2 had wound gape.

The special attributes and features of compression suture are:

- Simplicity of application.

- Lifesaving potential.

- Relative safety.
- Capacity for preserving the uterus and thus subsequent fertility.

- Satisfactory hemostasis can be assessed immediately after application.

- Its tensile strength is reduced in $48 \mathrm{hrs}$, so it exerts no permanent damage to uterus.

- Effective when applied in the hypotensive patient (compression hemostasis). On return of normal pulse pressure, hemostasis is maintained.

- If the procedure fails, other radical procedure can always be considered.

In conclusion, present initial series of cases of PPH treated with compression suture procedure shows that it is an effective method of controlling PPH. It should be attempted as early as possible in order to maximize its success and prophylactic application should always be considered in patients at high risk of atonic PPH. Application of a compression suture should be taught to all trainees and registrars in obstetrics. Its relative simplicity and ease of application, its life saving potential, relative safety and above all its capacity for preserving the uterus, make it the recommended procedure of choice if conservative measures do not control PPH, and should be attempted before any radical surgery is considered.

\section{CONCLUSION}

This study evaluates the use of compression suture in the management of Atonic PPH, after vaginal delivery and during caesarean section with failed medical management. The evaluation was done in terms of efficacy of methods in reducing the blood loss and obviating the need for hysterectomy in total number of 60 cases. Compression sutures in treatment of Atonic PPH, after failed medical methods is the boon to treat and prevent further blood loss. It is a uterine conserving surgery in massive Atonic PPH. Postgraduate students in Obstetrics and Gynecology should be trained in using compression sutures. Among the different compression sutures; Modified B-Lynch i.e.; Hayman and Arulkumar suture is simple easy technique to apply for beginners and experts. Sooner the later, principle works in taking compression sutures within a time period prior to developing an irreversible shock. Short term complication are negligible, long term complications in the form of ischemia, necrosis are not reported much in literature.

\section{Funding: No funding sources}

Conflict of interest: None declared

Ethical approval: The study was approved by the Institutional Ethics Committee

\section{REFERENCES}

1. Arulkumaran S, Onning Tanizian. The management of postpartum haemorrhage. In: Arulkumaran, ed. The Management of Labour. $2^{\text {nd }}$ ed; 2006:208-228. 
2. DC Dutta: Complication of third stage of labour. In: Text book of Obstetrics. $7^{\text {th }}$ edition. 2013:410-417.

3. Registrar General of India in Health Information, India. Ministry of Health. New Delhi: 2008. Available at: https://mohfw.gov.in.

4. Koh E, Devendra K, Tanl. B Lynch suture for the treatment of uterine atony. Singapore Meds. 2009;50(7):693-7.

5. Khatoon A, Hasnny SF, Ansari J. B Lynch Brace suture for the treatment of major primary postpartum hemorrhage: an experience at Abbasi Shaheed Hospital, Karachi. Med Channel. 2011;17(3):36-8.

6. Quahba J, Picketty M, Huel C, Azarian M. Uterine compression sutures for postpartum bleeding with uterine atony. BJOG. 2007;114(5):619-22 .

7. Neelam N, Kumar SJ. B-Lynch suture-An experience. J Obstet Gynecol India. 2010;60(2):12834.

8. Tariq S, Wazir S, Moeen G. Efficacy of B-Lynch Brace Suture in Postpartum Haemorrhage. Annals King Edward Med Univ. 2011;17(2):116.

9. Marasingh JP, Condous G, Seneviratne HR, Marasingh U. Modified anchored B Lynch uterine compression suture for the postpartum bleeding with uterine atony. Acta Obstret Gynecol Scand. 2011;90:280-3.

10. Hackethal A, Bruggmann D, Oehmke F, Tinneberg HR. Uterine compression sutures in primary PPH after Caesarean section: Fertility Preservation with a simple and effective technique. Human Reprod. 2008;23(1):74-9.
11. Vachhani M, Virkud A. Prophylactic B-Lynch suture during emergency caesarean section in women at high risk of uterine atony: a pilot study. Internet $\mathbf{J}$ Gynecol Obstet. 2006;7(1):1-8.

12. Majumdar A, Mallick K, Vasava B, Desai K, Dalal M. A descriptive study on Hayman suture technique to control postpartum hemorrhage. Sri Lanka J Obstet Gynaecol. 2012;34(3).

13. Ghodke VB, Pandit SN, Umbardand SM. Role of modified B-Lynch suture in modern day management of atonic PPH. Bombay Hospital J. 2008;50(2):205-10.

14. Allerhdin S, Aird C, Darielian P. B-Lynch sutures for major primary PPH at caesarean delivery. Obstet Gynecol. 2006;26(7).

15. Kulsange P. Assessment of efficacy of modified Balogun-Lynch stitch in management of atonic postpartum haemorrhage. Int $\mathrm{J}$ Biomed Adv Res. 2014;5(5).

16. Kalkal N, Sarmalkar MS, Nayak AH. The effectiveness of b-lynch sutures in management of atonic postpartum haemorrhage during caesarean section. Int J Reprod Contracept Obstet Gynecol. 2017;5(9):2915-20.

Cite this article as: Gadappa SN, Gavit YB, Sharma D, Mahajan R. Study of efficacy of compression suture in the surgical management of atonic PPH. Int J Reprod Contracept Obstet Gynecol 2018;7:4261-6. 